\title{
Camanchaca. Flujos etnonímicos y neblineros en la costa norte de Chile ${ }^{1}$
}

\author{
Manuel Escobar M. ${ }^{2}$ y Magdalena García B. ${ }^{3}$
}

\begin{abstract}
RESUMEN
Se indaga la relación del término Camanchaca como denominador tanto de los habitantes del litoral desértico como de la neblina costera. Se explora el vínculo entre ambas entidades a partir de la posición de Camanchaca como etnónimo, su etimología y las transformaciones de su significado. Se complementa con la revisión de ciertos rasgos arqueológicos que actúan como testigos materiales de esta relación y que permiten posicionar a los oasis de niebla como parte del territorio de estos grupos. Este trabajo permite proponer una nueva hipótesis sobre el aún incierto origen del etnónimo, y plantear que el devenir del término para nombrar el fenómeno atmosférico es más bien tardí y habría estado influido por la producción de nuevos campos semánticos generados por los procesos migratorios acaecidos en tiempos del salitre y la chilenización.
\end{abstract}

Palabras clave: Camanchaca, etnónimo, desierto costero, oasis de niebla.

\begin{abstract}
This article explores the relation of the term Camanchaca as a common term for the inhabitants of the desert littoral and the coastal fog. The link between both meanings is examined by taking into account the word Camanchaca as an ethnonym, by reviewing its etymology, and the transformations of its meaning. We incorporate archaeological data that serve as a material correlation that allow us to situate fog oases as part of the territory inhabited by these groups. We postulate a new hypothesis for the origins of the ethnonym, and suggest that the shift to designate the atmospheric phenomenon occurredin later periods, possibly influenced by the production of new semantical fields produced by the migratory processes that took place during the nitrate boom and the process of chilenización.
\end{abstract}

Key word: Camanchaca, ethnonym, desert coastal, fog oases.

De forma independiente, ambos autores agradecen el patrocinio de Conicyt a través de la Beca de Doctorado Nacional. Asimismo, agradecen a los proyectos Fondecyt 1080458, 1130279 y 1110196, y al proyecto Residencia Artística Red Cultura (CNCA, resolución 1816) dirigido por Claudia del Fierro. También se agradece a los pobladores y pobladoras de Paposo por confiar y compartir sus conocimientos con los autores, especialmente a Rosa Salas. Por último, se agradece la valiosa colaboración de Victoria Castro, Lautaro Núñez, Raquel Pinto, Benjamín Ballester y Carola Flores. Y a Estefanía Vidal por la traducción del resumen. Artículo recibido el 20 de enero de 2017, aceptado el 18 de mayo de 2017 y corregido el 22 de septiembre de 2017.

Programa de Doctorado en Ciencias Sociales, Facultad de Ciencias Sociales, Universidad de Chile (Chile). E-mail: mem1074@gmail.com

Centro de Investigación del Hombre en el Desierto / Instituto de Arqueología y Antropología, Universidad Católica del Norte (Chile).

E-mail: manegarciab@yahoo.com 
Una antigua leyenda recopilada en el oasis de Pica cuenta que los habitantes de la costa de Tarapacá, "aprovechándose de la neblina, subían con ella hasta las altas tierras y asolaban los huertos en busca de la vegetación que ellos no tenían junto al mar. De ahí que los camanchangos o camanchacos sean los hombres de la camanchaca" (Bahamonde 1978: 78). Estando en Pica el año 2010 fue posible registrar la misma leyenda de la voz de un antiguo habitante, lo cual plantea su vigencia en dicho oasis hasta la actualidad. Asimismo, una versión ampliada también nos ha relatado el arqueólogo Lautaro Núñez,

"La versión original me la contó el ingeniero Bertie Humberstone, hijo de don Santiago Humberstone [1850-1939], fundador del sistema inglés Shank de la explotación salitrera. La recogió en Pica. El relato original es así: Los camanchacas eran indios de la costa que se preparaban para los tiempos en que esa neblina, como su nombre, subía a Pica. Cuando ocurría este fenómeno en tiempos de don Santiago, los piqueños decían 'ya vienen los camanchacos', aunque en esos tiempos ya los botines no ocurrían. Estaba en las memorias...eran eventos de un pasado antiguo... [los camanchacos] ascendían con ella y se apropiaban de los maíces guardados en los depósitos. Luego bajaban con el botín. He visto algunas veces en invierno este efecto. La camanchaca entra y hasta en el día no se ve claro a pocos metros. Esto debió ocurrir en invierno lo cual explica que se apropian de maíces embodegados (Lautaro Núñez, comunicación personal, 2016).

Los indígenas originarios de la costa desértica han pasado a la historia con los nombres de camanchacas o changos. Aún en la actualidad comúnmente son identificados como pescadores extintos que habitaban aproximadamente desde Tongoy hasta Arica y que construían balsas de cuero de lobo. Esta identificación se debe a un largo proceso derivado de los saberes locales, las descripciones de forasteros y algunos estudios. Proceso en el que se puede reconocer una primera etapa que hemos denominado la formación de un prototipo (Escobar, 2015), que se configuró a partir de los primeros relatos europeos (Feuillée, 1714 y Frezier, 1716; Hawkins, 1847 [1593]; Lizárraga, 1999 [1609]; Lozano de Machuca, 1885 [1581]; Pretty, 1904 [1587]; Vásquez de Espinoza, 1948 [1630]; Vaux, 1854 [1579]; Vivar, 1979 [1558]) y que se consolida en la segunda mitad del siglo XVIII cuando el término Chango comienza a aparecer regularmente en la documentación oficial (Bueno, 1763; Alcedo, 1786; Carvallo Goyeneche, 1876 [1796]; O'Higgins, 1929 [1789]). Y una segunda etapa, en que además comienzan a aparecer descripciones de estudiosos e investigaciones más específicas (Bollaert, 1860; Philippi, 1860; Latcham, 1910; D’Orbigny, 1945; Mellet, 1959 [1824]; Cúneo Vidal, 1913; Uhle, 1922; Santa Cruz, 1913; entre otros).

Pero es a finales de la década de 1970 con los trabajos de Bente Bittmann (1977) y Horacio Larraín (1978), quienes se abocaron de lleno a estas poblaciones desde el conocimiento arqueológico, antropológico y etnohistórico, que se logran los progresos más importantes hasta ese momento. Sin embargo, a pesar de que lograron ampliar, discutir y especificar el conocimiento existente, siguieron considerando a estos grupos como una sola etnia ${ }^{4}$, que se extendía desde el litoral ariqueño hasta el de la región de Coquimbo y que era posible identificar por un conjunto de rasgos característicos (cf. Larraín, 1978-79). Contribuyendo paradójicamente, a mantener el limitado imaginario común que enunciábamos más arriba.

Hay que distinguir que Bittmann, especialmente por su trabajo con los etnónimos (1984) que referiremos más adelante, era capaz de relativizar la idea de que fuera una sola etnia, al contrario de Larraín (1978). 
Actualmente, los avances de las investigaciones permiten complejizar esta representación, con nuevos datos derivados especialmente de las investigaciones arqueológicas, que muestran los vínculos y prácticas que tenían los pescadores con otros ámbitos socioculturales y geográficos. Por una parte, los contextos arqueológicos del borde costero señalan la relativa importancia que alcanzaron los recursos terrestres, particularmente restos óseos de guanaco (Lama guanicoe), cactáceas y bulbos comestibles, evidencias queno siempre han sido suficientemente valoradas (Schiappacasse y Niemeyer, 1984; Núñez y Moragas, 1977; Llagostera, 2005; Larraín, 19781979; Larraín et al., 2004; Zlatar, 1983; Ballester y Gallardo, 2011; Salazar et al., 2015). Asimismo, se ha venido documentando la existencia de un intenso tráfico entre la costa y el interior, incluyendo la movilidad de los pescadores hacia la cordillera de la Costa y la pampa, avalando una idea que ya estaba presente en el trabajo de Bitmann (1977). Específicamente, se ha demostrado que las poblaciones costeras hacían incursiones hacia el interior por senderos que aún se preservan, con el objetivo de buscar materias primas líticas fundamentales en sus kits de pesca, obtener minerales y vegetales cultivados (e.g. Ardiles et al., 2011; Ballester y Crisóstomo 2017; Blanco et al., 2017; Carrasco et al., 2017; Larraín y Bugueño 2011; Pimentel et al., 2011, Salazar et al., 2015). Junto con ello, en estos espacios distantes de la costa se describen también tumbas aisladas y sitios de arte rupestre igualmente vinculados a los cazadores-recolectores del litoral (Briones et al., 2005; Cases et al., 2008; Mostny y Niemeyer, 1984).

Por otra parte, también se han llevado a cabo análisis de documentos históricos que han permitido evaluar los procesos de continuidad y transformación sociocultural (Castro, 2009; Escobar, 2015; Letelier, 2011). Esta nueva información diversifica las caracterizaciones socioculturales y por tanto refuerzan la conjetura de que no sería una sola etnia (Cassasas, 1974) y de cierto modo acotan la extensión geográfica de estas poblaciones a la costa desértica de Tarapacá y Atacama, aunque sin negar la existencia de incursiones a mayores latitudes. Esto último es relevante, pues la popularización del término Chango ha implicado la identificación equivocada de grupos pescadores 5 .

De este modo, en coherencia con las nuevas investigaciones, planteamos algunas ideas e interrogantes en torno a los etnónimos y la territorialidad de los pescadores que surgen de la lectura de la leyenda citada. En primer lugar, la leyenda muestra la vigencia del etnónimo Camanchaca hasta épocas contemporáneas, lo cual es relevante si consideramos que éste desaparece de las fuentes documentales hace más de tres siglos, durante la segunda mitad del siglo XVII. Asimismo, considerando que camanchaca como nombre de la niebla, recién se masifica en los documentos a comienzos del siglo XX, la leyenda se convierte en el único relato al cual hemos podido acceder donde aparecen ambas acepciones asociadas y donde se establece una primera relación explícita al respecto. Junto con plantear la persistencia del etnónimo en las memorias locales -a contrapelo de los documentos-, la leyenda establece una analogía entre ambas entidades costeras, los pescadores de Tarapacá y la niebla, en términos de un supuesto patrón de movilidad que sería característico de ambos, con una direccionalidad desde la costa Pacífica hacia el interior. Asimismo, el relato presenta a la niebla como un elemento de identidad, dejando entrever que éste no sería una autoidentificación, sino un nombre dado desde afuera, en este caso por parte

Un caso extremo de esto es la monografía de Valparaíso de Víctor Domingo Silva (1910: 17), donde relata que en el siglo XVI había indios pescadores de raza Chango en las riberas de Valparaiso, que navegaban en sus balsas de cuero de lobo y que llegaban incluso hasta Quiriquina en la actual región del Biobío. 
de los agricultores de Pica, aunque no elimina la posibilidad de que la niebla sea un elemento de identidad de los mismos pescadores, que supuestamente reproducen su comportamiento y la usan a su favor para camuflarse.

¿Cuál es el trasfondo de esta homologación? ¿Camanchaca fue primeramente niebla o etnónimo? ¿De dónde proviene la palabra, qué estaría representando? ¿Cuáles son los discursos tras este etnónimo? ¿El ejercicio de una práctica, de un patrón de movilidad? ¿Los efectos de un fenómeno atmosférico? Y en ese contexto ¿qué importancia tuvieron los oasis de niebla para los pescadores? ¿Qué nos dicen los contextos arqueológicos al respecto?

\section{Los oasis de niebla}

Los "oasis de niebla" son ecosistemas que se distribuyen de forma discontinua a lo largo de la cordillera de la Costa entre el sur de Perú -donde éstos se denominan "lomas"- y el norte de Chile, gracias a la humedad que provee la niebla costera o camanchaca. Ésta ingresa al continente desde el océano Pacífico gracias a la acción constante de los vientos del Sur y Suroeste y al estancarse en las serranías costeras, generan condiciones de humedad que permiten sustentar los oasis de niebla (Follman y Weisser, 1966; Muñoz et al., 2001; Pinto, 2005; Pinto y Luebert, 2009; Finger y Teillier, 2010). En puntos de mayor altitud, existen oasis con una biodiversidad inusitada, como Alto Patache y Paposo, donde se reportan ocupaciones humanas en épocas prehispánicas, históricas y contemporáneas.

Por una parte, en Alto Patache, región de Tarapacá, se han descrito más de setenta especies de plantas entre hierbas anuales y perennes, arbustos y cactáceas que conviven con diferentes especies de aves que actúan como polinizadores, además de lagartos, zorros y guanacos (Núñez y Varela, 1967-68; Muñoz et al., 2001; Pinto, 2005; Larraín et al., 2004; Pinto y Luebert, 2009). En este ambiente, Larraín y equipo (2004) describen una serie de sitios arqueológicos que denotan ocupaciones transitorias que evocan la realización de tareas específicas, incluidas recolección de plantas, caza de guanaco, obtención de materias primas líticas e incluso de agua dulce, utilizando vasijas cerámicas como "atrapanieblas" (Larraín et al., 2004). Asimismo, estos autores destacan la alta densidad de puntas de proyectil asociadas a la caza de guanaco (Lama guanicoe) así como la presencia de "cantidades apreciables de restos de bulbos o bulbos secos de Leucocoryne, Zephira y/o Fortunatia spp., obviamente consumidos y llevados por el hombre antiguo como fuente de hidratos de carbono y suplemento de su dieta" (Larraín et al., 2004: 363).

Bulbos similares a los descritos por Larraín y colaboradores (2004) han sido reportados en distintos contextos arqueológicos ubicados entre la desembocadura de Camarones y el río Loa, abarcando el borde costero de toda la región de Tarapacá. Con distintos niveles de precisión los antecedentes aluden a la presencia de envolturas fibrosas y discos basales de bulbos (cormos) costeros en el conchal de Camarones 14 (García y Belmonte, 2016), el cementerio Cáñamo 1 (Núñez y Moragas, 1977), el cementerio Los Verdes 1 y conchal Los Verdes 2 (Sanhueza, 1985), los conchales Los Verdes 9, Chomache 1 y Pabellón de Pica (Vidal y García, 2009) y los cementerios de la desembocadura del río Loa (Carrasco et al., 2017). Asimismo, en las cercanías de estos sitios se han descrito varias aguadas, algunas de ellas alimentadas completamente de la caman- 
chaca, las cuales, a juicio de Núñez y Varela (1967-1968) permiten comprender la subsistencia en la costa arreica.

Por otra parte, en Paposo, región de Antofagasta, los abundantes bancos de niebla que se producen entre los 300 y 900 m s.n.m., también activan una densa flora y fauna (Núñez y Varela, 1967-68; Follman y Weisser, 1966; Gutiérrez y Lazo, 1996). Follman y Weisser (1966) señalan que la vegetación en el oasis de niebla de Paposo se distribuye en franjas segregadas por la altura, predominando en el primer estrato las cactáceas, luego los arbustos achaparrados y espinosos y a mayor altura los cactus columnares y claveles del aire (Tillandsialandbeckii). Además, al igual que en la costa de Tarapacá, en el sector de Paposo se describen una serie de vertientes dispersas en una extensión de más de cien kilómetros, alimentadas de las napas freáticas y la camanchaca (Núñez y Varela, 1967-1968; Gutiérrez y Lazo, 1996).

A mediados del siglo XIX, se describía el paisaje de Paposo "como cerros altos cubiertos de vegetación abundante, aunque macilenta y triste. En ellos los ganados pacen alfilercillo, malva, mostaza, cañayuyo, nudillo, pajonal, al que después de arraigado se ha visto verde diez años sin Iluvia. Se encuentran copiosas manadas de huanacos, tras de los cuales van también leones que los cazan" (Gutiérrez y Lazo, 1996: 15). El ganado que forrajea en el oasis de niebla forma parte de una actividad que se inicia a fines del siglo XVII con la instalación de una estancia ganadera donde también había huertos (Philippi, 1860; Gutiérrez y Lazo, 1996). En particular, Philippi describe que a media legua al sur de Paposo, la costa forma un llano bajo que llega hasta el pie de los cerros donde "hay como veinte casas de Changos" (Philippi, 1860: 22). Este llano coincide con el sector que los paposinos actuales denominan "Rinconada" o ..."El Rincón", un sector particularmente húmedo cubierto permanentemente por la niebla, donde mantienen residencias secundarias orientadas a la crianza de vacunos, caprinos y aves de corral, así como huertos familiares. Varias personas en Paposo señalaron la importancia que tenía anteriormente la caza de guanaco (Lama guanicoe), así como también la recolección de plantas silvestres "del cerro", comestibles y medicinales, entre las cuales se destacó el "cebollín" y la papa chiñaque, usadas por sus abuelos como alimento, acompañando mariscos y otras preparaciones. En nuestra incursión a El Rincón en compañía de un paposino, observamos algunos ejemplares de cebollín en proceso de germinación. Un ejemplar colectado fue posteriormente identificado como Leucocorynesp., el mismo género registrado por Larraín y equipo (2004) en Alto Patache.

En relación a los bulbos, las referencias arqueológicas de la costa de Tarapacá y los registros etnográficos llevados a cabo en Paposo señalan la importancia que tenían los bulbos como alimento, lo cual ha sido ratificado también por la botánica Raquel Pinto (comunicación personal 2016). Su presencia en los conchales y cementerios prehispánicos mencionados así como su ausencia en los sitios prehispánicos del interior (cf. Núñez, 1979; García et al., 2014), plantea que el consumo de estos bulbos forma parte de una práctica alimenticia exclusiva de las poblaciones costeras, desde el 7000 AC al 1450 DC, a juzgar por las dataciones disponibles en los sitios donde fueron hallados (Camarones 14, Cáñamo 1, Los Verdes 1, 2 y 9, Chomache 1, Pabellón de Pica y desembocadura del Loa). Finalmente en Paposo, si bien no hay evidencias -hasta el momentodel consumo de bulbos en tiempos prehispánicos, la arqueología documenta la ocupación de este oasis de niebla a partir del sitio El Médano (1500 m s.n.m.), reconocido ampliamente por sus pinturas rupestres donde los pescadores representaron ejemplares de fauna marina y escenas de caza de camélidos aparentemente guanacos (Mostny y Niemeyer, 1984; Berenguer, 2009). 


\section{Algunas claves para la lectura de etnónimos en las fuentes documentales ${ }^{6}$}

Es común en la literatura que las designaciones que identifican etnias sean puestas en entredicho y que por lo general no siempre haya una versión de las propias sociedades respecto de cómo se designan, y cuando las hay, nos enteramos que son diferentes a las que se les había impuesto. Es lo que ocurre, por ejemplo, con los actuales Mapuche respecto de los etnónimos Araucano y Mapuche, que se confrontan a la temprana autoidentificación de Reche (cf. Boccara, 2007 [1998]). Lo mismo sucede para el caso del etnónimo Uru, como denominador de los grupos de pescadores que habitaban el eje acuático del altiplano (que como veremos más abajo también aparece usado para nombrar a los pescadores de la costa Pacífica), el cual corresponde a una noción despectiva impuesta por los aymara, borrando así los etnónimos kot'suns, u "hombres del lago" y jas-shoni u "hombres de agua", como se autodeterminaban los uros del Titicaca y los uru-chipayas, respectivamente (Wachtel, 2001).

En este sentido, como indica Viveiros de Castro, la mayoría de las veces la conformación de un etnónimo, pareciera corresponder a una equivocación de quién lo registra. Y agrega que "Tampoco es casualidad que la mayoría de los etnónimos amerindios que han pasado a la literatura no sean autodesignaciones, sino nombres (frecuentemente peyorativos) dados por otros pueblos" (Viveiros de Castro, 2004: 50). Lo anterior señala que la objetivación etnonímica repercute fundamentalmente en los otros, y no sobre quien está en la posición de sujeto. Así, los etnónimos serían nombres de terceros, asociados a la categoría de "ellos" y no a la de "nosotros".

Concordante con lo anterior, José Luis Martínez ha propuesto una entrada para comprender el despliegue de estos procesos en las sociedades andinas. Continuando según sus propias palabras el camino abierto por Lorandi, Saignes, Platt y Bouysse (Martínez, 1995), plantea que los documentos del siglo XVI que hacen referencia a los grupos humanos de la región Circumpuneña, emplean categorías descriptivas similares, estereotipos repetidos, maneras de referirse a los grupos indígenas que tienden a borrar diferencias existentes entre ellos, terminando por unificarlos social y culturalmente, más allá de su probable situación de "periferia" en relación a los grupos nucleares. "Se trata de un conjunto de prácticas que me han llevado a plantear la existencia, en el siglo XVI de lo que podríamos llamar un 'discurso', con reglas de enunciación propias, con estructuras semánticas, etc. sobre ellos" (Martínez, 1995: 34). Discurso que está basado en las percepciones y representaciones que parecen haber producido las sociedades andinas dominantes, sobre las poblaciones y sus territorios. Asimismo, reflexiona cómo la construcción de identidad de otro u otros, conlleva siempre el surgimiento de una forma social para referirse a ellos, estableciendo pautas y usando categorías que clasifican, ordenan y jerarquizan, lo que deben ser las relaciones entre unos y otros. Para el caso de las sociedades andinas, estos discursos constituirían lo que el autor llama una "mirada étnica", la que se manifestaría en la generación de nombres, apelativos, categorías socioculturales, entre otras, a la cual fue accediendo a través de fuentes coloniales, específicamente crónicas y diccionarios de las lenguas quechua y aymara.

Junto a esta "mirada étnica", otra autora ha señalado que durante la primera etapa de colonización, para los europeos el "más importante criterio de clasificación de los individuos es la pertenencia a la clase rica o pobre, y no un criterio de clasificación étnico -aunque sí, éste, puede ser eventualmen- 
te un indicio de poder económico-" (Bouysse-Cassagne, 1975: 328), lo que grafica las concepciones ideológicas con que se producían sus descripciones. Sin embargo, Martínez $(1995,2004)$ insiste que esta situación también debió estar influida por la "mirada étnica", por los discursos que las sociedades andinas dominantes habían establecido con anterioridad para identificar a esos otros grupos, y que los españoles también utilizaron para la elaboración de sus propias redes de denominaciones. Es lo que permite sugerir que, en ese proceso, las asignaciones de etnónimos estuvieron sujetas a la presencia de algún europeo con conocimientos empíricos pero especulativos y de la capacidad que tenía para "bautizar" a los habitantes sin necesidad de certezas. Se entiende, por tanto, que es muy probable que haya habido más de un grupo étnico, no obstante, debido a estas identificaciones externas -cuzqueñas, aymaras, atacameñas o españolas- no hayan sido reconocidas u obviadas rápidamente.

Más analíticamente, para comprender este proceso son pertinentes las ideas de Fredrik Barth, en cuanto a la importancia que se les atribuye a los grupos étnicos como portadores de cultura ${ }^{7}$, "lo que propendería a identificar y distinguir a los grupos étnicos por las características morfológicas de las culturas de que son portadores" (Barth, 1976: 12). Rasgos que el autor propone que sean considerados como una implicancia o resultado, más que como una característica primaria y definitiva de la organización del grupo, de lo contrario se corre el riesgo de clasificar a los individuos como miembros de un grupo étnico, dependiendo del nivel que muestren de aspectos morfológicos de esa cultura, convirtiendo las diferencias entre grupos en simples distinciones de un inventario de rasgos, dejando de lado lo fundamental para una adscripción étnica que son las categorías y prejuicios de los actores.

Como se ve, esto se adecúa bastante bien a lo que planteamos sobre los rasgos más visibles, que fundan las características generalizadas de los grupos costeros del desierto, y que por supuesto, al ser asumidos como determinantes identitarios, no permitieron el reconocimiento de un nivel de adscripción más interno de cada individuo con su grupo. De este modo, el proceso de denominación de las poblaciones costeras significó que los europeos agruparan a todos los grupos costeros en una misma categoría. Así, la variabilidad de etnónimos documentados aluden más bien a quién los nombra y, en este sentido, no refiere a la potencial diversidad étnica. Dicho de otra forma, igualaron a estas poblaciones a un "tipo" que se podía observar a lo largo de la costa. Un elemento unificador en este sentido fueron las balsas de cuero de lobo, rasgo llamativo y determinante en las observaciones europeas, puesto que su eficiencia llevó a que su uso se extendiera más allá de los límites de la costa desértica, llegando incluso a la zona del Maule (Looser, 1938). Asimismo, la mayoría de los registros destacan la simplicidad material que permite el océano y el clima del litoral norte, lo que se refleja en vestimentas y viviendas ligeras y por sobre todo la posibilidad abundante de la recolección y pesca, que genera una disposición particular en cuanto a los procesos productivos y reproductivos, que por lo general tienden a la escasa acumulación y a la poca necesidad de ella.

\section{Breve referencia a los etnónimos del desierto costero}

La problemática de los etnónimos en la costa desértica ha sido un tema trabajado desde hace mucho (Bittmann, 1977, 1979; Boman, 1908; Casassas, 1974; Castro, 2001, 2009; Cúneo Vidal, 1913,

No es aquí el lugar indicado para exponer los cuestionamientos acerca del concepto de cultura, pero quisiéramos establecer que concordamos principalmente respecto de aquellos que dan cuenta de las tendencias esencialistas de ciertas conceptualizaciones (cf. Ortner 2016), que por lo demás esta cita a Barth, en parte se hace cargo. 
1915, 192?; Hidalgo, 1981; Martínez, 1990, 1998; Murra, 1964; Rostworowski, 1986; Wachtel, 2001). A pesar de las diversas y sugerentes interpretaciones, la falta de documentación no nos permite avanzar en el reconocimiento de estos grupos costeros en términos étnicos. El estudio más acabado sigue siendo el de Bittmann (1984), quien continuando los trabajos que le precedieron y agregando algunos datos, logró compilar la mayoría de los registros de los distintos etnónimos.

De lo estudiado, se pueden reconocer dos aspectos principales. Por un lado, el problema del origen de las palabras, en tanto herramientas de clasificación para terceros, "heredadas por los españoles de los grupos políticamente dominantes, en particular los aymaras y los inkas" (Martínez, 1998: 65), lo que expresaría además la ignorancia y prejuicios de los colonizadores. Y el otro, la incertidumbre acerca de si estas denominaciones estarían indicando grupos étnicos, o como proponen otros investigadores, estarían haciendo referencia más bien a categorías religiosas, sociales o de especializaciones productivas (Martínez, 1990, 1998; Murra, 1964). A lo que habría que agregar una cuestión relevante, que en ningún texto se explicita si las personas se identificaban con alguna de esas denominaciones.

La referencia más antigua de estos etnónimos es la presentada por Cúneo Vidal, quien cita un documento de 1550 sobre el traspaso de la encomienda de Lucas Martínez Vegazo a Jerónimo de Villegas, donde se identifica a Choquechambi "cacique de los uros sujetos y de los pescadores camanchacos que están en la costa" (Bittmann, 1984: 108). Además, indica que en documentos de los Archivos del cabildo de Arica, en los primeros años de la colonia, a los indios de las caletas entre el río Camarones y Loa, se les llamaba indios Pica y Loa (1915: 304), lo que podría hacer referencia al vínculo de éstos con el interior, aunque como advierten algunos investigadores (Castro, 2009: 103; Wachtel, 2001: 572), hay que tomar con precaución las informaciones de este autor pues no siempre se encuentran sus referencias.

Sin embargo, lo relevante es que tempranamente son dos los etnónimos que aparecen designando a los pobladores de la costa, Uru y Camanchaca, a los que se agregarán posteriormente Proanche y Chango. De estos últimos, el primero registrado únicamente a mediados del siglo XVII en el Libro de Varias Ojas de la parroquia de Chiuchiu (Casassas, 1974), y el segundo, también apareciendo a medidos de ese siglo, en un documento fechado en 1659 referenciado por Santa Cruz (1913) que es establecido por Bittmann (1984) como la referencia más antigua. No obstante, Castro (2009: 512) presenta otro registro derivado de la Probanza de Méritos del cura Francisco de Otal, que está fechado unos veinte años antes, lo que permite suponer que su uso es incluso anterior.

A partir de la información existente (cf. Casassas, 1974; Bittmann, 1984), de estos cuatro etnónimos es posible considerar que tanto Camanchaca como Proanche, parecieran ser las denominaciones más vinculables a grupos originarios del litoral desértico, independientemente que hayan sido determinadas por terceros y no reconocidas por los propios aludidos. Pues como se verá más adelante, Camanchaca aparece muy temprano y de alguna manera persiste inclusive después de caer en desuso, a través de la versión que indica que de allí derivaría Chango, a pesar que existen documentos que los mencionan como dos grupos distintos (cf. Castro, 2009; Santa Cruz, 1913).

Aunque Murra especificamente está escribiendo acerca del grupo Uru mencionado en la Visita de Garci Diez, puede ser extensiva su opinión a las poblaciones costeras en particular y como método generalizado de los europeos para nombrar a las poblaciones indígenas. 
Y en cuanto a Proanche, no solo aparece abiertamente distinguiéndose de Camanchaca en registros de alianzas matrimoniales, sino que también debido a los lugares del que son naturales las personas así identificadas, pertenecientes a un tramo más meridional de la costa arreica. Pues si bien comparte con Camanchaca Cobija y Puerto Loa, hay proanches naturales de Morro Moreno (norte de Antofagasta) y de Copiapó; este último, centro administrativo eclesiástico, del litoral que va entre dos localidades importantes de población costera originaria, como eran Paposo y Caldera (cf. Sayago, 1973; Lazo y Téllez, 1984; Gutiérrez y Lazo, 1996, entre otros)9.

Por su parte, el etnónimo Uru no refiere directamente a las poblaciones del desierto costero, sino que a una asimilación a grupos de pescadores del altiplano de Bolivia (Wachtel, 2001), aunque no es descartable, como insinúan algunas fuentes, que hayan existido grupos urus en la costa del Pacífico debido a procesos migratorios (cf. Cúneo-Vidal, 1913; Hidalgo, 2004).

\section{Noticias sobre el etnónimo Camanchaca}

Luego de la primera referencia de 1550, la denominación Camanchaca se encuentra en un relato español sobre la expedición de Francis Drake a la actual región de Antofagasta, a pesar de que la versión inglesa del relato (Vaux, 1854) no mencione el etnónimo. Esto induce a pensar que tal vez el autor español, bien informado de los pobladores locales, agregó la denominación que él conocía. El informe es de 1579 y comenta cómo los piratas ingleses encontraron en una isleta a cuatro indios camanchacas con quienes interactuaron (Bittmann, 1984). En el siglo siguiente, está el relato de fray Reginaldo de Lizárraga, quien informa que habitaban entre el Loa y Copiapó, en "algunas caletillas con poca agua salobre, donde se han recogido y huido algunos indios pescadores, pobres y casi desnudos [...] su comida sola es pescado y marisco. Llaman á estos indios Camanchacas" (1999 [1603-9]).

También en el siglo XVII el cronista Joan Santacruz Pachacuti Yamqui, en su relato de las conquistas del Inca Pachacutec Yupanqui hacia el Condesuyo y el Collao, menciona que este Inca "... yendo por el Collao, en donde topa con los yndios Ccoles y Camanchacas, grandes hechizeros..." (Santacruz Pachacuti, 1879 [1608]: 279). Esto indicaría que los camanchacas llegaban, aunque fuera excepcionalmente, a la costa meridional del Perú, mientras que la expresión "hechiceros" podría identificar a gente muy alejada de la religión imperial (Hidalgo, 2004; Castro, 2009). Bittmann (1984: 122-124) refrenda lo anterior, a partir de un relato hallado en la Colección "Egerton 1816" del Museo Británico de Londres, de fecha desconocida pero seguramente del siglo XVI, proporcionado al Capitán Francisco de Cadres por un indio nombrado Chepo, de unos 115 o 120 años de edad, quien le comenta acerca de viajes marítimos que hacían indígenas desde los puertos de Arica e Ylo; sobre uno de ellos, le comenta de un grupo de indígenas que había en una isla en el sur de Perú y que hablaban la lengua de don Sebastián Camanchac. Dato que para la autora indicaría, que los camanchacas estaban en esa zona en condición de extranjeros, o que por lo menos se distinguían como grupo lingüístico.

La identificación de un grupo costero más meridional, también es reconocida por Latcham, Uhle, Santa Cruz y D'Orbigny (Casassas, 1974: 19), pero bajo la denominación Chango, que a pesar que desde la segunda mitad del siglo XVIII se había convertido en un genérico para nombrar a los grupos de todo el desierto costero, igualmente estos investigadores están reconociendo la existencia de un grupo distinto desde la desembocadura del río Loa o Cobija, hacia el sur. Que a pesar del problema de la diferencia en las denominaciones, se podrían asociar a los identificados como Proanche. 
Para el siglo XVII se encuentran las referencias del "Libro de Varias Ojas", ahí se usa para denominar a personas de Cobija y Tocopilla (región de Antofagasta). Acerca de esos registros, Bittmann (1984) hace una anotación interesante, respecto a que no se conoce la forma en que se transmite el etnónimo, ni para los camanchacas, ni para los otros; no se sabe si es a través de la madre, del padre, o de ambos. En las inscripciones de matrimonio aparecen anotados sólo uno de los contrayentes, ambos, o a veces a los hijos y no a los padres, o a los padres, sin que se les asigne a los hijos. En esto nuevamente ronda la idea de que las designaciones étnicas en realidad estarían sujetas a la evaluación y asignación por parte de quien escribía los documentos, y no necesariamente por las identidades propias de los indígenas. Podríamos pensar que en el caso en que se les asignaba un etnónimo a los padres y no a los hijos, era para "cristianizar" a esos niños y que dejaran de ser "salvajes" o, al contrario, en el caso en que los hijos aparecían bajo una denominación étnica, a diferencia de los padres, podría ser para subrayar que aún no estaban bautizados y que en algún momento deberían estarlo.

Finalmente, un dato importante es la relación de los etnónimos Camanchaca y Chango, donde este último vendría del primero producto de su dinámica de uso en el tiempo. "De Camanchacos el uso vulgar hizo: Camanchangos y, luego, abreviando: Changos, nombre viviente" (Cúneo-Vidal, 1915: 304). Aunque este planteamiento carece de respaldo documental preciso que lo valide, nos parece sugerente, toda vez que no existen otras noticias que permitan conjeturar más claramente de dónde viene Chango y la similitud que vincula las palabras hacen plausible la transformación.

\section{De cómo el etnónimo devino en niebla}

Junto al posicionamiento de Chango como el único denominador de las poblaciones costeras, Camanchaca en algún momento pierde esa capacidad y pasa a ser en un segundo momento el denominador de la neblina litoral. Como ha sido expuesto, sabemos que los registros más tardíos de su presencia como etnónimo son de la segunda mitad del siglo XVII. Luego en el siglo XVIII, pareciera desaparecer. La hegemonía del etnónimo Chango atraviesa la centuria, Ilegando al final de ese período convertido incluso en la denominación escrita y oficial del campo de la producción de conocimientos (Bueno, 1763; Alcedo, 1786; Carvallo Goyeneche, 1876; O'Higgins, 1929) ${ }^{10}$. Durante el siglo XIX, tampoco conocemos registros de la palabra Camanchaca en tanto etnónimo, las referencias de ese siglo son respecto de indios pescadores o de changos (cf. Bollaert, 1860; D’Orbigny, 1945; Larraín, 1979; Philippi, 1860, entre otros). Sin embargo, es durante la última década de ese siglo, que la noción comienza a ser publicada identificando a la neblina. Primero en el diccionario enciclopédico español de Zerolo (1895), que la define como neblina tarapaqueña, y luego en "Jeografía Descriptiva de la República de Chile" (Espinoza, 1897), que hablando de la provincia de Tarapacá indica que a la garúa costera allí la nombran camanchaca. A diferencia de lo que sucede con publicaciones de la década anterior, como "Jeografía Náutica de la República de Chile" (1880) de Vidal Gormaz, que para la zona de Antofagasta solo la nombra como garúa, igual

\footnotetext{
La incorporación del término Chango en el imaginario colectivo sobre las poblaciones indígenas y su posicionamiento como único etnónimo, puede ser concebida como un primer hito en el devenir de la tradición costera desértica, que implica entre otras cosas, la pérdida definitiva del carácter étnico de estos grupos, y su conversión en un modo de vida, que los procesos históricos venideros le permitieron subsistir mediante transformaciones hasta el día de hoy (Escobar, 2015).
} 
que para el tramo entre Mejillones y Arica (2013), lo que permitiría suponer que antes de la última década deI XIX, aún era solo parte del conocimiento local tarapaqueño.

Más allá de su uso local, el posicionamiento del término como neblina costera en fuentes documentales se afianza comenzando el siglo XX. Así lo indican fundamentalmente los estudios lexicográficos de chilenismos de esa época, lo cual nos lleva a suponer que serían las poblaciones que han inmigrado al Norte Grande por la minería, las que, retomando la noción local asociada al fenómeno atmosférico, la incorporan al uso común y luego la expanden a través de las redes que los conectan hacia el sur, explicando en parte que haya sido añadida a la producción lexicográfica chilena.

Nos aventuramos con esta hipótesis, pues en los primeros diccionarios de chilenismos editados en la segunda mitad del siglo XIX, período en que se está formando esta población minero-nortina inmigrante y desarrollando un campo de sentido lingüístico"11, no contienen la palabra Camanchaca (Echeverría y Reyes, 1900; Ortúzar, 1893; Rodríguez, 1875). Ésta recién aparece a comienzos del siglo XX, cuando el proceso de chilenización del Norte Grande se ha fortalecido. Tal como se lee en Román (1901-8) y Lenz (1904), y posteriormente en Valenzuela (1918) o Medina (1928). A los que se agregan dos diccionarios propios del ámbito pampino, Bertrand (1919) y Echeverría y Reyes (1929) ${ }^{12}$.

La mayoría de esos registros, lo asocian a una neblina baja y densa, que pertenece a la región de Tarapacá. Sin embargo, es interesante constatar que no la vinculan directamente al ambiente de la costa, aunque estaría implícito, lo que entendemos se debe a que surge de un ámbito de referencia pampino, o de una mirada desde el interior de la región. Es lo que se lee: "En Chile y el Perú, llámase así la niebla espesa y baja que reina en el desierto de Tarapacá" (Román, 1901-8), "Neblina o llovizna nocturna que cae en las provincias septentrionales" (Valenzuela, 1918), "Neblina espesa y baja que reina en el desierto de Tarapacá" (Medina, 1928), "Neblinas arrastradas muy húmedas, que prevalecen en Tarapacá" (Bertrand, 1919) y "Neblina muy húmeda y espesa que suele empobrecer el caliche en pampa" (Echeverría y Reyes, 1929). Siendo la referencia de Lenz (1904), la única que la vincula directamente "la densa llovizna o neblina nocturna que cae en la costa de las provincias del norte de Chile y en la pampa del Tamarugal". La que entendemos, es la explicación más precisa.

Respecto a su etimología, solo los textos de Lenz y de Valenzuela hacen proposiciones. El primero indica que sería quechua, pero que no la encontró en los diccionarios; y el segundo escribe que viene "del quichua y aymará. Camac, el que produce, o hace, y de Cchaca, ronquera= que causa ronquera, o resfrío" (Valenzuela, 1918). Esta significación, que según nuestras indagaciones es la primera vez que aparece, será reproducida luego en Silva (1938), Moesbach (1952), Meyer (1952) y Grau (2000). Todas, sin referencias que las justifiquen mayormente ${ }^{13}$.

\footnotetext{
1 Es lo que establece por ejemplo J. A. González, quien argumenta que entre 1883 y 1930, se "asiste a la gestación de la identidad cultural regional" (1996: 51). Respecto del origen de estos inmigrantes y su reclutamiento, es vital reconocer en el proceso migratorio, el dispositivo conocido como enganche, mediante el cual se alistó a personas de muchos lugares (cf. Bravo, 1983; Sabella, 1959; González, 2002).

12 La brecha que se produce entre este último y el diccionario de 1900 donde no había registrado Camanchaca, sirve para representar el proceso que expandió la noción de neblina tarapaqueña, al alero del proceso de formación social señalado.

13. Otra referencia etimológica aparece en Pulgar (1971), quien al describir la región peruana de chala o costa, indica en una nota al pie, que en el sur de Perú y en Chile se le dice camanchaca o camanchala a la niebla costera, término que derivaría de "camac-chala" que significaría "niebla continua" o "gran niebla", pero tampoco es muy preciso en indicar la procedencia del término.
} 
Hemos revisado el diccionario de quechua de Guardia (1970) y el diccionario colonial de González Holguín (1608). En ambos aparece la palabra Cchaca, con significado de ronco o afónico, para el primero, y asociada a ese campo semántico, en el segundo. Lo que, sin embargo, no nos convence de que valide el significado "lo que produce ronquera o resfrío". En cuanto a la palabra Kamanchaka, si bien aparece en el diccionario de Guardia, él mismo indica que no es quechua, sino que sería de origen uru-atacameño. En el diccionario de González Holguín no se encuentra.

La palabra Camanchaca vuelve a relacionarse al etnónimo en Guevara (1925), quien destaca la observación de Lizárraga y la asocia a los changos a través de la derivación ya presentada. A pesar de que Santa Cruz ya lo había hecho al referenciar la encomienda de 1659, "Ios indios cananchacas y chiangos pescadores y no pescadores que de mi encomienda estuvieren en Cobija..." (1913: 16), lo que le hizo interpretar que esos cananchacas no eran pescadores. Es recién entrado los años setenta, junto a los estudios de Casassas (1974) y Bittmann (1977), que se vuelve a reconocer su cualidad de etnónimo más ampliamente, que como hemos visto, se extenderá hasta las investigaciones actuales. Así como sucede con la publicación del "Diccionario de Voces del Norte de Chile" de Bahamonde (1978), que recoge la voz Camanchaca como neblina, Camanchacos como nombre primitivo de los Changos, y Camanchangos como una forma primitiva de la nominación changos. Argumentando que todavía en la región de Pica existe la leyenda que citamos al inicio, que los identifica como "los hombres de la camanchaca". Definiciones que son retomadas en el "Diccionario de pesca artesanal del Norte Grande de Chile" (Van Kessel, 1986). No obstante, este rescate se da fundamentalmente en el mundo académico y particularmente en el campo de los especialistas en el tema, siendo la noción Chango la que sigue predominando como etnónimo, así como Camanchaca continúa representando mayoritariamente a la neblina costera. Esto se evidencia en el último estudio lexicográfico de chilenismos, el "Diccionario de uso del español de Chile" (2010), así como se puede constatar en el uso corriente de la palabra actualmente.

De la lectura de los antecedentes lexicográficos citados, se puede colegir que el vínculo entre el etnónimo y la denominación del fenómeno atmosférico, pareciera que se da porque la neblina adquiere un nombre, y los costeros, que pertenecen al espacio de donde proviene, lo adquieren por añadidura. Es lo que también sugieren algunos especialistas (Bahamonde, 1978; Bowman, 1942; Martínez, 1998; Pérez, 1990; Rostworowski, 1986; Van Kessel, 1986; Wachtel, 2001), pero esta conjetura a pesar de sus argumentos, nos parece que no tiene mayor sustentación que la palabra y la ubicación geográfica del fenómeno. Es por eso que quisiéramos revertir esa idea. No sería la neblina la que nombra a los costeros, sino que a través de la denominación de los grupos indígenas se nombró luego a la neblina.

¿Pero cómo podríamos establecer esta inversión, si lo que sabemos de Camanchaca como etnónimo es tan poco preciso? Primero, tratando de asociar el etnónimo a esas poblaciones. Es lo que hemos intentado basándonos en las ideas y método presentados por Martínez (1995), iniciando con la relectura del único párrafo de los documentos coloniales que tratan de explicar el término: "Llaman á estos indios Camanchacas, porque los rostros y cueros de sus cuerpos se les han vuelto como una costra colorada, durísimos; dícen les previene de la sangre que beben de los lobos marinos, y por este color son conocidísimos" (Lizárraga, 1999 [1603-9]: 121).

A partir de allí, como ya habíamos revisado sin resultados los diccionarios quechua, comenzamos a buscar en el "Vocabulario de la lengua Aymara" de Bertonio (1612). Como dice la descripción de Lizárraga acerca de los rostros de los pescadores, buscamos por duro y costra, pero como 
no encontramos coincidencias, decidimos buscar directamente por la palabra Camanchaca, que tampoco entregó resultados. No obstante, dimos con una palabra similar y que su significado nos pareció que se relacionaba a lo que sabemos de los costeros y, por tanto, se presentaba como una huella posible de rastrear y de proponer como alternativa explicativa del etnónimo.

La palabra es ccamachatha, que significa secar frutas y otras cosas (Bertonio, 1612: 41) ${ }^{14}$. Que si bien en un comienzo relacionamos a la posible sequedad o dureza de los rostros que describe Lizárraga (1999 [1603-9])15, creemos mucho más certera la asociación al pescado seco o salado. En ese caso, sería una identificación a través de una actividad laboral que era parte importante del vínculo que establecían los costeros con las poblaciones del interior, tal y como hemos visto en la mayoría de las informaciones que grafican su intercambio (Lozano de Machuca, (1581) 1885; Bittmann, 1977, 1984; Martínez, 1985; Hidalgo, 2004), siendo especialmente manifiesto el relato de Vásquez de Espinoza, "en aquella costa se haze grandissima pesca [...] muchos generos de pescados, que salpresan y del se lleuan grandes recuas de carneros a Potosi, Chuquisaca, Lipes y a todas aquellas prouincias de la tierra de arriba, por que es el trato principal de aquella tierra, con que an enrriquesido muchos" (1948 [1630]: 618).

Por tanto, el etnónimo Camanchaca entraría en lo que Martínez llama la "mirada étnica" de los grupos dominantes, "sobre la cual -en un momento- ya no se reflexiona sino que, simplemente, se usa o se impone" (Martínez, 1995: 35), y que como citábamos más arriba, implicaría una tendencia a borrar las diferencias étnicas existentes entre los distintos grupos, identificándolos únicamente con las actividades de subsistencia costera. De hecho el mismo autor argumenta que en "ciertos casos, las especializaciones laborales también daban origen a los nombres de una colectividad" (Martínez, 2004: 508) ${ }^{16}$.

De esta forma, Camanchaca podría haber sido la deformación por parte de los españoles de la palabra ccamachatha, que estaría indicando a quienes producían y abastecían a los pueblos del interior de pescado seco, que para el fragmento de la costa en que principalmente aparece asociado el etnónimo Camanchaca, es posible vincularlo con los señoríos aymaras. Seguramente por eso la dificultad de vincular Camanchaca al léxico quechua.

\section{Palabras finales}

Como hemos expuesto, el tema de los etnónimos de los pescadores del desierto costero aún se mantiene en la incertidumbre, pues ninguna de las definiciones realizadas es determinante. Es en ese contexto, que nuestro trabajo ha querido aportar a la discusión articulando la información disponible y otorgando nuevos datos e interpretaciones para sostener una nueva posibilidad.

\footnotetext{
De la segunda parte del vocabulario.

15 Es importante señalar, como arista que se agrega a la potencial profundización de esta búsqueda, que Santa Cruz (1913) cree que la palabra cananchaca (camanchaca) vendría de la palabra atacameña cachaca, que significa lugar áspero. A lo que Casassas (1974: 41) agrega la definición de Vaïsse (1896) ckatchacka: áspero, terreno muy pedregoso.

16 Es necesario indicar que Martínez $(1995,2004)$, basa sus reflexiones principalmente en los discursos cuzqueños, pero no en forma excluyente, y es por eso que nos atrevemos hacer esta conjetura a través de un diccionario aymara, pues como explica es sobre todo por una cuestión metodológica, en la que, si bien el discurso cuzqueño es el pilar fundamental, igual sus textos incluyen lo que se sabe de los conocimientos discursivos aymaras.
} 
Proponemos que Camanchaca habría sido primeramente etnónimo y de ahí habría sido usado para denominar a la neblina, a diferencia de la mayoría de las otras propuestas que sugieren la situación inversa. Por lo general sustentadas en definiciones poco certeras de vocablos indígenas y en correlaciones sin origen etimológico entre la palabra y la neblina, situación que en cierta medida estaría influida por la pérdida de la cualidad etnonímica del término. Por otra parte, etimológicamente, algunas argumentaciones plantean un origen quechua, como Lenz (1904) que lo sugiere, pero no encuentra la palabra en los diccionarios o Valenzuela (1918) que postula una mezcla entre aymara y quechua que no es precisa, así como Guardia (1970) que indica que no sería quechua, sino que de origen uru-atacameño, cuestión que tampoco hemos podido corroborar.

Es por eso que nos hemos atrevido a plantear que la palabra ccamachatha de origen aymara y que significa secar frutas y otras cosas (Bertonio, 1612), podría asociarse al campo semántico de camanchaca y en este sentido haber sido utilizada por esas poblaciones, para denominar a los grupos costeros de quienes obtenían pescado seco. Los europeos habrían aprendido y deformado la denominación y en su necesidad colonialista se la adjudicarían a grupos que necesitaban identificar.

Si bien el etnónimo se mantiene en el ámbito local, en las fuentes documentales éste pierde relevancia en el siglo XVIII cuando se impone el etnónimo Chango, que continua hasta el presente como nombre de los pescadores originarios de la costa desértica. Sin embargo, Camanchaca, sedimentada en las memorias locales tarapaqueñas, es retomada por las nuevas generaciones de nortinos, derivando al nombre de la niebla. No obstante, otros autores atribuyen el sentido inverso, es decir que camanchaca primeramente se liga a la niebla y desde ahí a los pescadores, pero como hemos notado, consideramos que esta tesis es débil, pues las evidencias lexicográficas no son precisas y porque camanchaca como etnónimo aparece antes en la documentación existente.

Independiente de lo anterior, camanchaca señala un vínculo simbólico entre las poblaciones costeras y la niebla, el cual adquiere nuevas dimensiones al momento de llevar a cabo la revisión arqueológica. En este sentido, las ocupaciones costeras atestiguadas en la Cordillera de la Costa y la pampa, así como la presencia de recursos terrestres en los conchales y cementerios del litoral, permiten plantear que los oasis de niebla también debieron formar parte del "paisaje chango" (sensu Castro et al. 2012) en el sentido de estar articulado a su quehacer cotidiano junto con las actividades de caza, pesca y recolección marina. Más aún, las evidencias a las que nos hemos referido, que incluyen recursos de subsistencia y manifestaciones rupestres como las pinturas de El Médano, representan expresiones elocuentes de la apropiación tanto efectiva como simbólica por parte de los pescadores de este espacio. Por ello, el vínculo manifiesto por la materialidad no solamente se halla en lo simbólico, sino que aparentemente refiere a una relación social y económica, que podría ser también territorial, como ha sido documentado para los casos de Alto Patache y Paposo.

Es por eso, que antes de cualquier disquisición lingüística, quisiéramos subrayar que ambas entidades son la expresión de un vínculo que los años y la historia han opacado, trayendo como consecuencia que el imaginario acerca de estas poblaciones las presente casi exclusivamente ligadas al mar, lo que afortunadamente ha comenzado a cambiar con las investigaciones más contemporáneas, que han ampliado considerablemente su representación. 


\section{Referencias bibliográficas}

ACADEMIA CHILENA DE LA LENGUA. Diccionario de uso del español de Chile. Santiago de Chile: Asociación de Academias de la Lengua Española, MN Editorial, CNCA, 2010.

ALCEDO, A. Diccionario geográfico histórico de las indias occidentales. O América. Madrid: imprenta de Benito Cano, 1786.

ARDILES, H.; BALLESTER, B. y CLAROT, A. Elección de dieta en poblaciones pasadas de la costa de la II región: una mirada multidisciplinaria. En: DIBAM. Fondos de apoyo a la investigación patrimonial. Informes. Antofagasta: Dibam, 2011, p. 83-110.

BAHAMONDE, M. Diccionario de voces del Norte de Chile. Santiago de Chile: Editorial Nascimiento, 1978.

BALLESTER, B. y CRISÓSTOMO, M. Percutores líticos de la pampa del desierto de atacama (norte de Chile): tecnología, huellas de uso, decoración y talladores. Chungara, 2017, Vol. 49, № 2, p. 175-192.

BALLESTER, B. y GALLARDO, F. Prehistoric and historic networks on theAtacama Desert coast (northern Chile). American Antiquity, 2011, № 85, p. 1-15.

BERENGUER, J. Las Pinturas de El Médano, norte de Chile: 25 años después de Mostny y Niemeyer. Boletín del Museo Chileno de Arte Precolombino, 2009, Vol. 14, № 2, p. 57-95.

BARTH, F. Introducción. En: BARTH, F. Los grupos étnicos y sus fronteras: la organización social de las diferencias culturales. México D. F.: Fondo de Cultura Económica, 1976, p. 9-49.

BERTONIO, L. Vocabulario de la lengua Aymara. Chucuito: Casa de la Compañía de Jesús por Francisco del Canto, 1612.

BERTRAND, A. Vocabulario Pampino Salitrero. Revista Caliche, 1919, № 6, p. 217-220.

BITTMANN, B. Notas sobre poblaciones de la costa del norte grande chileno. En: CASASSAS, J.M. Aproximación a la etnohistoria del norte de Chile. Antofagasta: Universidad del Norte, 1977, p. 56115.

BITTMANN, B. Cobija y sus alrededores en la época colonial (1600-1750). Actas del VII Congreso de Arqueología de Chile 1977 Vol. II. Santiago de Chile: Kultrún, 1979, p. 327-363.

BITTMANN, B. Programa Cobija: Investigaciones Antropológico-multidisciplinarias en la Costa Centro Sur Andina: Notas Etnohistóricas. En: MASUDA, S. Contribuciones a los Estudios de los Andes Centrales. Tokio: Universidad de Tokio, 1984, p. 101-148.

BLANCO, J.; CORREA, I.; FLORES, C. y PIMENTEL, G. La extracción prehispánica de recursos minerales en el internodo Quillagua-Costa, desierto de Atacama. Estudios Atacameños, 2017 (en prensa). 
BOCCARA, G. Los vencedores. Historia del pueblo Mapuche en la época colonial. Antofagasta: Línea Editorial IIAM, 2007.

BOLLAERT, W. Antiquarian, ethnological and other research in New Granada, Ecuador, Peru and Chile, with observations of the pre-incarial, incarial and other monuments of peruvian nations. London: Trubner and Co., 1860.

BOMAN, É. Antiquités de la región andine de la RépubliqueArgentine et du désert d'Atacama. Tome Premier. Paris: Imprimerie Nationale, 1908.

BOUYSSE-CASSAGNE, T. Pertenencia étnica, status económico y lenguas en Charcas a fines del siglo XVI. En: COOK, D.N. Tasa de la Visita General de Francisco de Toledo. Lima: Universidad Nacional Mayor de San Marcos, 1975, p. 312-328.

BOWMAN, I. Los senderos del desierto de Atacama. Santiago de Chile: Sociedad Chilena de Historia y Geografía Imprenta Universitaria, 1942.

BRAVO, P. Los Enganchados en la era del salitre. Madrid: LAR Ediciones, 1983.

BRIONES, L.; NÚÑEZ L. y STANDEN, V. Geoglifos y tráfico prehispánico de caravanas de llamas en el desierto de Atacama (norte de Chile). Chungara, 2005, Vol.37, № 2, p. 195-223.

BUENO, C. Descripción de las Provincias pertenecientes al Reyno del Perú, Chile y el Río de la Plata. Según el orden con que las dio al público. Lima: 1763.

CARVALLO GOYENECHE, V. Segunda parte de la Descripción histórico-jeográfica del Reino de Chile. Cap. V-VI. En: Colección de Historiadores de Chile y documentos relativos a la Historia Nacional. Tomo X. Santiago de Chile: Imprenta de la librería del Mercurio, 1876, p. 64-73.

CARRASCO, C.; CORREA, I.; BELMAR, C.; BALLESTER, B. y GALLARDO, F. Cocinando relaciones interculturales: residuos adheridos en vasijas cerámicas de grupos cazadores recolectores marinos del desierto de Atacama (periodo formativo, Norte de Chile). Estudios Atacameños, 2017 (en prensa).

CASASSAS, J.M. La Región Atacameña en el siglo XVII. Datos históricos socioeconómicos sobre una comarca de América meridional. Antofagasta: Universidad del Norte, 1974.

CASES, B.; REES, C.; PIMENTEL, G.; LABARCA, R. y LEIVA, D. Sugerencias desde un contexto funerario en un 'espacio vacío' del desierto de Atacama. Boletín del Museo Chileno de Arte Precolombino, 2008, Vol.13, No 1, p. 51-70.

CASTRO, V. De ídolos a santos. Evangelización y religión andina en los Andes del sur. Santiago de Chile: Fondo de publicaciones americanistas, Universidad de Chile / Centro de Investigaciones Diego Barros Arana y DIBAM, 2009. 
CASTRO, V. Atacama en el tiempo. Territorios, identidades, lenguas. (Provincia El Loa, II Región). Anales de la Universidad de Chile, 2001, №13. Disponible en internet: http://www.anales.uchile.cl/ index.php/ANUC/article/viewArticle/2527/2442

CASTRO, V.; ALDUNATE, C. y VARELA, V. Paisajes culturales de Cobija, costa de Antofagasta, Chile. Revista Chilena de Antropología, 2012, Vol. 26, p. 97-128.

CÚNEO VIDAL, R. Puntos fundamentales para el estudio de la historia y la geografía de Arica. Boletín de la Sociedad Geográfica de Lima, 1913, Tomo XXIX, p. 171-174.

CÚNEO VIDAL, R. De algunas etimologías del bajo Collasuyo (Urin Collasuyo) de los incas. Revista Chilena de Historia y Geografía, 1915, Tomo XIII, primer trimestre, № 17, p. 295-305.

CÚNEO VIDAL, R. Historia de la Civilización peruana. Contemplada en sus tres etapas clásicas de Tiahuanaco, Hattun Colla y el Cuzco. Barcelona: Casa editorial Maucci, 192?

D’ORBIGNY, A. Viaje a la América Meridional: Brasil, República del Uruguay, República Argentina, La Patagonia, República de Chile, República de Bolivia, República del Perú: realizado de 1826 a 1833. Buenos Aires: Editorial Futuro, 1945.

ECHEVERRIA y REYES, A. Voces usadas en Chile. Santiago de Chile: Imprenta Elzeviriana, 1900.

ECHEVERRIA y REYES, A. Voces Usadas en la Industria Salitrera. Antofagasta: Imprenta y Litografía Skarnic, 1929.

ESCOBAR, M. La presencia de lo omitido: el devenir de la tradición costera en Atacama. Santiago de Chile: Tesis para optar al grado de Magíster en Estudios Latinoamericanos, Facultad de Filosofía y Humanidades, Universidad de Chile, 2012.

ESCOBAR, M. El devenir de la tradición desértico costera en Atacama. En: GIPART. Estudios sociales del mar, regiones costeras y sus recursos. Identidad, territorio y economía política. Santiago de Chile: Editores GIPART - Libros del Perro Negro, 2015, p. 173-192.

ESPINOZA, E. Jeografía descriptiva de la república de Chile. Santiago de Chile: Imprenta i encuadernación Barcelona, 4ª edición, 1897.

FEUILLÉE, L. Journal des observations physiques, mathematiques et botaniques. Tome Second. Paris: Rue S. Jacques, 1714.

FINGER, K. y TEILLIER, S. Contribución al conocimiento de la flora endémica de Taltal y Paposo, región de Antofagasta (II), Chile. Chlorischilensis, 2010, Vol. 13, № 2. Disponible en internet: http:// www.chlorischile.cl

FOLLMAN, G. y WEISSER, P. Oasis de neblinas en el norte de Chile. Boletín de la Universidad de Chile, 1966, Nº 67, p. 34-38. 
FREZIER, M. Relación del Viaje por el mar del sur a las costas de Chile i el Perú. Durante los años 1712, 1713 i 1714. Santiago de Chile: Traducido por Nicolás Peña, Imprenta Mejía, 1902.

GARCÍA, M.; VIDAL, A.; MANDAKOVIC, V.; MALDONADO, A.; PEÑA, M.P. y BELMONTE, E. Alimentos, tecnologías vegetales y paleoambiente en las aldeas formativas de la pampa del Tamarugal, Tarapacá (ca. 900 a.C.-800 d.C.). Estudios Atacameños, 2014, № 47, p. 33-58.

GARCÍA, M. y BELMONTE, E. Las plantas conocidas y amadas por los pescadores Chinchorro. Inventario de un legado etnobotánico. En: ARRIAZA, B. y STANDEN, V. La Cultura Chinchorro: pasado y presente. Arica: Ediciones Universidad de Tarapacá, 2016, p. 119-134.

GONZÁLEZ, H.D. Vocabulario de la lengua general de todo el Perú llamada lengua qquichua o del inca. Ciudad de Los Reyes: Francisco del Canto, 1608.

GONZÁLEZ, J. A. Elementos de discusión para definir la identidad cultural del Norte Grande. Revista Norte, 1996, № 1, p. 47-61.

GONZÁLEZ, S. Hombres y Mujeres de la Pampa. Santiago de Chile: LOM ediciones, $2^{\text {a }}$ edición, 2002.

GRAU, J. Voces Indígenas. De uso común en Chile. Santiago: Ediciones Oikos, 3a edición, 2000.

GUARDIA, C. Diccionario Kechwa-Castellano castellano-Kechwa. Lima: Ediciones Peisa, $4^{a}$ edición, 1970.

GUEVARA, T. Historia de Chile. Chile Prehispano. Santiago de Chile: Balcells \& Co., 1925.

GUTIÉRREZ, G. y LAZO, L. Plantas medicinales silvestres de uso tradicional en la localidad de Paposo, Costa del Desierto de Atacama, Il Región, Chile. Taltal: Fondo de Desarrollo de las Artes y la Cultura, Ministerio de Educación, 1996.

HAWKINS, R. The observations of Richard Hawkins in his voyage into the south sea in the year 1593. London: Hakluyt Society, 1847.

HIDALGO, J. Culturas y etnias protohistóricas: área andina meridional. Chungara, 1981, № 8, p. 209-253.

HIDALGO, J. Pescadores del litoral árido de valles y quebradas del norte de Chile y su relación con agricultores, siglo XVI y XVIII. En: HIDALGO, J. Historia Andina en Chile. Santiago de Chile: Editorial Universitaria, 2004, p. 431-469.

LARRAíN, H. Análisis demográfico de las comunidades de pescadores changos del Norte de Chile en el siglo XVI. New York: Tesis para optar al grado de Master of Arts in Department of Anthropology, State University of New York, 1978. 
LARRAíN, H. Identidad cultural e indicadores eco-culturales del grupo étnico chango. Revista Norte Grande 1978-1979, №6, p. 63-76.

LARRAÍN, H. Cobija y el interior de Antofagasta en 1864, relato de un viaje. Actas del VII Congreso de Arqueología de Chile 1977 Vol. II. Santiago de Chile: Kultrún, 1979, p. 429-441.

LARRAÍN, H.; VELÁSQUEZ, F.; LÁZARO, P.; CERECEDA, P., OSSES, P. y PÉREZ, L. Un yacimiento de cazadores-recolectores marinos en la terraza litoral de Bajo Patache, sur de lquique. Polis, 2004, Vol. 2, No 7. Disponible en internet: http://polis.revues.org/6320

LARRAÍN, H. y BUGUEÑO V. Presencia de un ayllu de camanchacas en el puerto de lquique en el siglo XVII. Revista de Geografía Norte Grande, 2011, №50, p. 7-21.

LATCHAM, R. Los Changos de las costas de Chile. Santiago de Chile: Imprenta Cervantes, 1910.

LAZO, L. y TÉLLEZ, E. Los Changos del distrito del Paposo a fines de la colonia: matrícula inédita de habitantes de una población costeña. Revista Futuro, 1984, № 7, p. 12-50.

LENZ, R. Diccionario etimolójico de las voces chilenas derivadas de lenguas indijenas americanas. Santiago de Chile: Imprenta Cervantes, 1904.

LETELIER, J. Clasificando indios, un ejemplo de la construcción de la categoría Changos durante el siglo XVI y XVII en la zona de la actual provincia del Loa. Taltalia, 2011, № 4, p. 103-115.

LIZÁRRAGA, R. Descripción Breve de toda la tierra del Perú, Tucumán, Río de la Plata y Chile. Buenos Aires: Academia Nacional de la Historia, 1999.

LLAGOSTERA, A. Culturas costeras precolombinas en el Norte chileno: secuencia y subsistencia de las poblaciones arcaicas. En: FIGUEROA, E. Biodiversidad Marina: Valoración, Usos y Perspectivas ¿Hacia dónde va Chile? Santiago de Chile: Editorial Universitaria, 2005, p. 107-148.

LOOSER, G. Las balsas de cuero de lobos de la costa de Chile. Revista Chilena de Historia Natural, $1938, N^{\circ} 42$, p. $232-266$.

LOZANO DE M., J. Carta del Factor de Potosí Juan Lozano Machuca al Virrey del Perú, en donde describe la Provincia de los Lipes de Diciembre de 1581. En: MINISTERIO DE FOMENTO DE PERÚ. Relaciones Geográficas de Indias. Tomo II. Madrid: Tipografía de Manuel G. Hernández, 1885, p. $21-28$.

MARTÍNEZ, J.L. Asentamientos y acceso a recursos en Atacama (s. XVII). En: Economía y Comercio en América Hispana. Santiago de Chile: Serie Nuevo Mundo, Cinco siglos, 1990, p. 13-62.

MARTÍNEZ, J.L. Entre plumas y colores aproximaciones a una mirada cuzqueña sobre la puna salada. Memoria Americana, 1995, Nº 4, p. 33-56. 
MARTÍNEZ, J.L. Pueblos del Chañar y el Algarrobo. Los Atacamas en el siglo XVII. Santiago de Chile: DIBAM, 1998.

MARTÍNEZ, J.L. Discursos de Alteridad y conjuntos significantes andinos. Chungara, 2004, Vol. 36, No2, p. 505-514.

MEDINA, J.T. Chilenismos. Apuntes Lexicográficos. Santiago de Chile: Sociedad Imprenta y Litografía Universo, 1928.

MELLET, J. Viajes por el interior de la América Meridional 1808-1820. Santiago de Chile: Editorial del Pacífico, 1959.

MEYER, W. Voces indígenas del lenguaje popular sureño 550 chilenismos. Padre Las Casas: Imprenta San Francisco, 1952.

MOESBACH, E. Voz de Arauco. Explicación de los Nombres Indígenas de Chile. Padre Las Casas: Imprenta San Francisco, 2a edición, 1952.

MOSTNY, G. y NIEMEYER, H. Arte rupestre en El Médano, II Región. Revista Creces, 1984, Vol.9, № 5, p. 2-5.

MUÑOZ, M.; PINTO, R.; MESA, A. y MOREIRA, A. "Oasis de niebla" en los cerros costeros del sur de Iquique región de Tarapacá, Chile, durante el evento El Niño 1997-1998. Revista Chilena de Historia Natural, 2001, Vol. 74, p. 389-405.

MURRA, J. Una apreciación etnológica de la Visita. En: DIEZ DE SAN MIGUEL, G. Visita hecha a la Provincia de Chucuito por Garci Diez de San Miguel el año 1567. Lima: Ediciones de la Casa de la Cultura, 1964, p. 421-442.

NÚÑEZ, L. Emergencia y desintegración de la sociedad tarapaqueña: riqueza y pobreza de una quebrada del norte chileno. Atenea, 1979, № 439, p. 163-213.

NÚÑEZ, L. y MORAGAS, C. Una ocupación con cerámica temprana en la secuencia del distrito de Cáñamo (costa desértica del norte de Chile). Estudios Atacameños, 1977, Vol. 5, p. 21- 49.

NÚÑEZ, L. y VARELA, J. Sobre los recursos de agua y el poblamiento prehispánico de la costa del Norte Grande de Chile. Estudios arqueológicos, 1967-1968, N³-4, p. 7-41.

O'HIGGINS, A. La visita a las provincias del norte. Revista Chilena de Historia y Geografía, 1929, № 67, p. 118-135.

ORTNER, S. Antropología y teoría social. Cultura, poder y agencia. San Martín: Universidad Nacional de General San Martín, Unsam edita, 2016.

ORTÚZAR, C. Diccionario manual de locuciones viciosas y de correcciones del lenguaje. Santiago de Chile: Imprenta Salesiana, 1893.

PÉREZ, E. Ch,amaka, "Se fue con la Camanchaca". Revista Camanchaca, 1990, No 11, p. 8-12. 
PHILIPPI, R. Viage al desierto de Atacama. Hecho de orden del Gobierno de Chile. En el verano 1853-54. Santiago de Chile: Halle en Sajonia, Librería de Eduardo Antón, 1860.

PIMENTEL, G.; REES, C.; DE SOUZA, P. y ARANCIBIA, L. Viajeros costeros y caravaneros. Dos estrategias de movilidad en el período Formativo del Desierto de Atacama, Chile. En: NÚÑEZ, L. y NIELSEN, A. En Ruta. Arqueología, Historia y Etnografía del Trafico Sur Andino. Córdoba: Grupo editor encuentro, 2011, p. 43-81.

PINTO, R. Tillandsia del norte de Chile y del Extremo Sur del Perú. Santiago de Chile: Editorial Gas Atacama. 2005.

PINTO, R. y LUEBERT, F. Datos sobre la flora vascular del desierto costero de Arica y tarapacá, Chile, y sus relaciones fitogeográficas con el sur de Perú. Gayana Botánica, 2009, Vol. 66, № 1, p. 28-49.

PRETTY, F. The prosperous voyage of M. Thomas Candish esquire into the South Sea, and so round about the circumference of the whole earth, begun in the yere 1586 and finished 1588 . In: HAKLUYT, R (editor). The principal navigations, voyages, traffiques \& discoveries of the English nation made by sea or over-land to the remote and farthest distant quarters of the earth at an time within the compasse of these 1600 yeeres: Volume 11. Glasgow: Robert Maclehose Company Ltd for The University Of Glasgow Press, 1904.

PULGAR, J. Geografía del Perú. Las ocho regiones naturales. Lima: Editorial Universo, 1971.

RODRÍGUEZ, Z. Diccionario de chilenismos. Santiago de Chile: Imprenta de "El independiente", 1875.

ROMÁN, M. A. Diccionario de chilenismos y otras voces y locuciones viciosas. Santiago de Chile: Imprenta de "La revista católica", 1901-1908.

ROSTWOROWSKI, M. La región del Colesuyu. Chungara, 1986, № 16-17, p. 127-135.

SABELLA, A. Norte Grande. Santiago de Chile: Editorial Orbe, $2^{\circ}$ edición, 1959.

SALAZAR, D.; FIGUEROA, V.; ANDRADE, P.; SALINAS,H.; OLGUÍN, L.; POWER, X.; REBOLLEDO, S.; PARRA, S.; ORELLANA, H. y J. URREA. Cronología y organización económica de las poblaciones arcaicas de la costa de Taltal. Estudios Atacameños, 2015, Vol. 50, p. 7-46.

SANHUEZA, J. Poblaciones tardías en playa Los Verdes, costa sur de lquique, I región, Chile. Chungara, 1985, Vol. 14, p. 45-60.

SANTA CRUZ, J. Los Indígenas del Norte de Chile, antes de la conquista española. Revista Chilena de Historia y Geografía, 1913, Tomo VII, p. 38-88.

SANTACRUZ PACHACUTI, J. Tres Relaciones de antigüedades peruanas. Madrid: Ministerio de Fomento, 1879. 
SAYAGO, C. Historia de Copiapó. Buenos Aires: Editorial Francisco de Aguirre, 2ª edición, 1973.

SCHIAPPACASSE, V. y NIEMEYER, H. Arcaico Temprano en la Quebrada de Camarones. Santiago de Chile: Museo Nacional de Historia Natural, Publicación Ocasional, 1984, Nº 41.

SILVA, C. Breve Diccionario Enciclopédico Chileno. Santiago de Chile: Ediciones Ercilla, 1938.

SILVA, V.D. Monografía histórica de Valparaíso. 1536-1910. Viña del Mar: Ediciones Altazor, 2004.

UHLE, M. Fundamentos étnicos y arqueología de Arica y Tacna. Quito: Imprenta de la Universidad Central, 1922.

VÁSQUEZ DE E., A. Compendio y Descripción de las Indias Occidentales. Washington: Smithsonian Institution, 1948.

VAÏSSE, E. Glosario de la lengua atacameña. Santiago de Chile: Imprenta Cervantes, 1896.

VALENZUELA, A. Glosario Etimológico de nombres de hombres, animales, plantas, ríos y lugares, y de vocablos incorporados en el lenguaje vulgar, aborígenes de Chile, y de algún otro país americano. Santiago de Chile: Imprenta Universitaria, 1918.

VAUX, W. The World encompassed by Sir Francis Drake: being his next voyage to that to Nombre de Dios. London: The Hakluyt Society, 1854.

VIDAL, A. y GARCÍA, M. Uso del espacio e interacción con la flora de la costa de Tarapacá. Análisis del material vegetal de asentamientos vinculados al Periodo Formativo. Informe proyecto Fondecyt 1080458, 2009.

VIDAL G., F. Jeografía Náutica de la República de Chile. Entrega Tercera. Santiago de Chile: Imprenta Nacional, 1880.

VIDAL G., F. Geografía náutica de Chile. Santiago de Chile: Pontificia Universidad Católica de Chile / Cámara Chilena de la Construcción / DIBAM, 2013.

VIVAR, G. Crónica y relación copiosa y verdadera de los reinos de Chile.. Berlín: Edición de L. Sáez-Godoy, Biblioteca Iberoamericana, 1979 [1558].

VIVEIROS DE CASTRO, E. Perspectivismo y multiculturalismo en la América indígena. En: SURRALLÉS, A. y GARCÍA, P. Tierra adentro. Territorio indígena y percepción del entorno. Lima: IWGIA, 2004, p. 37-80.

WACHTEL, N. El regreso de los antepasados. Los indios urus de Bolivia, del siglo XX al XVI. México D.F.: Fondo de Cultura Económica, 2001.

ZEROLO, E. Diccionario enciclopédico de la lengua castellana. Paris: Garnier Hermanos, 1895.

ZLATAR, V. Replanteamiento sobre el problema Caleta Huelén 42. Chungara, 1983, Vol. 10, p. 21-28. 